Revista da Rede Brasileira de História da Geografia e Geografia Histórica

4 - 5 | 2003

Território

\title{
A estruturação da tecnoburocracia do planejamento territorial no Brasil
}

\section{Roberto Schmidt de Almeida}

\section{OpenEdition}

\section{Journals}

Edição electrónica

URL: https://journals.openedition.org/terrabrasilis/356

DOI: 10.4000/terrabrasilis.356

ISSN: 2316-7793

\section{Editora}

Rede Brasileira de História da Geografia e Geografia Histórica

\section{Edição impressa}

Data de publição: 1 janeiro 2003

ISSN: 1519-1265

\section{Refêrencia eletrónica}

Roberto Schmidt de Almeida, «A estruturação da tecnoburocracia do planejamento territorial no Brasil», Terra Brasilis [Online], 4 - 5 | 2003, posto online no dia 05 novembro 2012, consultado o 05 dezembro 2022. URL: http://journals.openedition.org/terrabrasilis/356 ; DOI: https://doi.org/10.4000/ terrabrasilis.356

Este documento foi criado de forma automática no dia 5 dezembro 2022.

All rights reserved 


\title{
A estruturação da tecnoburocracia do planejamento territorial no Brasil
}

\author{
Roberto Schmidt de Almeida
}

\section{0 papel do Estado brasileiro nos anos 30 e sua burocracia}

1 É perfeitamente reconhecida pela historiografia a importância da Era Vargas (1930-1945 e 1951-1954) na gestação de um Brasil industrial e urbano, contrapondo-se ao velho Brasil agrário (Fausto, 1987; D'Araujo, 1999; Pandolfi, 1999).

2 A concepção de um governo central forte, quebrando as espinhas das lideranças estaduais, impondo uma nova diretriz de crescimento econômico e, ao mesmo tempo, organizando um quadro institucional e jurídico capaz de garantir às populações urbanas acesso a esse mundo novo tem motivado estudos e interpretações acadêmicas as mais diversas.

3 Constituem exemplo desse interesse avaliações como a de Skidmore (1975), que costura inteligentemente as tramas políticas e econômicas envolvidas no processo; de Villela e Suzigan (1975), em trabalho clássico sobre as políticas econômicas de governo gestadas entre 1889 a 1945; e de Baer (1966) sobre as relações entre a industrialização e o processo de desenvolvimento econômico do Brasil, com ênfase no período Vargas. Este último livro, a partir de sua segunda edição, conta também com mais dois artigos: o de Baer, Villela e Kerstenetsky (1975), sobre o papel do Estado na economia (principalmente no que se refere à indústria estatal), e o de Baer e Villela (1975) sobre os estágios do crescimento industrial brasileiro. Tais estudos são obras de referência fundamentais para a compreensão do período em questão.

4 Mais recentemente, o importantíssimo ensaio de Bielschowsky (1995), já considerado um clássico pelos pesquisadores de História Econômica no Brasil, analisa o ciclo ideológico do desenvolvimentismo rastreando as correntes do pensamento econômico 
que vigoraram no país entre 1930 e 1964 - neoliberalismo, desenvolvimentismo e socialismo.

5 É também de grande importância o estudo de Motoyama e colaboradores (1994) sobre os processos de maturação da Ciência e Tecnologia no Brasil, através da luta interna e externa para a estruturação de um projeto autônomo de desenvolvimento nuclear, iniciado no segundo governo Vargas por iniciativa do Contra-Almirante Álvaro Alberto de Motta e Silva e consubstanciado na criação do Conselho Nacional de Pesquisas em 1951. Um trabalho de autoria de Malan, Bonelli, Abreu e Pereira (1977), mostrando as conexões entre as políticas econômicas brasileiras no plano externo e o processo de industrialização ocorrido entre 1939 e 1952, finaliza essa pequena amostra de avaliações de diversas facetas do papel do Estado na Era Vargas.

6 No contexto que aqui nos interessa, Vargas, nos primeiros anos da década de 1930, inicia a política de criação de autarquias e conselhos nacionais que cuidariam de setores específicos (como nos casos dos Conselhos Nacionais de Estatística e de Geografia), ou de produtos considerados economicamente importantes (petróleo, café, açúcar, pesca, sal e mate), controlando a produção e estabelecendo preços mínimos. Estabelece um sistema de créditos de longo prazo para os estabelecimentos industriais e define o controle estatal da marinha mercante, com a estatização do Lloyd Brasileiro e das empresas de navegação da Amazônia e da Bacia do Prata.

7 Entre os anos da II Guerra Mundial e 1954 o Governo Federal utiliza o conceito de segurança nacional para criar uma série de empresas estatais estratégicas, que garantiriam nas décadas seguintes a ampliação do processo de industrialização, principalmente na Região Sudeste: Companhia Vale do Rio Doce (1942), Fábrica Nacional de Motores (1943), Companhia Nacional de Álcalis (1943), Companhia Siderúrgica Nacional (1946), Banco Nacional de Desenvolvimento Econômico (1952), para financiar projetos industriais de longa maturação. Fazem parte também desse período a criação da Petrobrás (1953), que instituiu o monopólio da extração e refino do petróleo e derivados, o início do processo de controle da geração e distribuição de energia elétrica e, ainda, o controle da produção, estoques reguladores, preços e distribuição atacadista de gêneros alimentícios básicos.

8 É possível perceber, pela magnitude das ações tomadas, a necessidade vital de mecanismos de controle do território, tais como: o conhecimento dos aspectos físicos da superfície e do subsolo, dos padrões espaciais da ocupação humana e econômica e de um ordenamento regional condizente com escala territorial do Brasil, além do seu mapeamento sistemático.

9 É com este pano de fundo que se deve avaliar em termos conceituais o papel da burocracia técnica que se estruturou no Governo Federal brasileiro, a partir dos anos 30, da qual o IBGE fez parte. Mas primeiramente devemos entender o que é e como evoluiu a burocracia.

O termo aparece na França em meados do século XVIII, nos escritos de Jean-Claude Marie Vincent de Gournay (1712-1759), num contexto de debate entre o absolutismo monárquico e o liberalismo econômico - o Laissez faire, laissez passer - do qual Gournay era um ferrenho partidário. Surge como uma crítica aos funcionários do governo monárquico que controlavam a maior parte das atividades econômicas do reino e se tornaram um estamento entre o povo e a nobreza, ao intermediarem as demandas 
entre estes e o rei. Tais atividades eram geralmente transferidas por herança, caracterizando um nepotismo brutal.

11 Dos direitos musicais e de apresentação teatral ao controle da distribuição de lenha, ou dos transportes de cabotagem fluvial, passando pela distribuição de livros, tudo era fiscalizado por esse corpo de funcionários reais que, obviamente, já praticava ainda atual política de criar dificuldades para vender facilidades.

Foi, porém, com o alemão Max Weber (1864-1920) que o termo passou a fazer parte importante do vocabulário da Sociologia, ao vincular-se ao estado moderno sob a forma do conjunto de atividades administrativas especializadas e controladas por um sistema racional e legitimado juridicamente, com o poder de dar ordens e fiscalizar as relações entre o Estado e a Sociedade.

Em Parlamentarismo e Governo numa Alemanha Reconstruída, Weber inicia o capítulo "Burocracia e Liderança Política" com as seguintes palavras:

Num Estado moderno necessária e inevitavelmente a burocracia realmente governa, pois o poder não é exercido por discursos parlamentares nem por proclamações monárquicas, mas através da rotina da administração. Isto é exato tanto com referência ao funcionalismo militar quanto ao civil. Mesmo o moderno oficial de patente superior trava batalhas de seu "gabinete". Tal como o assim chamado progresso em relação ao capitalismo tem sido o inequívoco critério para a modernização da economia, desde épocas medievais, assim também o progresso em relação ao funcionalismo burocrático caracterizado pelo formalismo de emprego, salário, pensão, promoção, treinamento especializado e divisão funcional do trabalho, áreas bem definidas de jurisdição, processos documentários, sub e super ordenação hierárquicas tem sido o igualmente inconfundível padrão para a modernização do Estado, quer monárquico, quer democrático, pelo menos no que se refere a um Estado composto por grandes massas de povo, e não a um pequeno cantão com administração rotativa (Weber 1974:16).

14 Como estudioso profundo da burocracia, Weber sabia dos problemas que poderiam advir de uma estrutura que cresce irresistivelmente e que se apresenta em caráter permanente nas grandes organizações. Para ele, no contexto do início do século XX, não era a ditadura do proletariado que iria se instaurar e sim a do burocrata. Neste início do século XXI, sua análise ainda continua válida.

Uma outra abordagem foi adotada por alguns sociólogos e historiadores brasileiros que trabalharam com o pressuposto de uma vinculação implícita entre as elites e a burocracia, principalmente quando referida aos altos postos de decisão e arbitragem. Nesta linha de raciocínio estão alguns importantes trabalhos como os de Sérgio Miceli (1979 e 1988) sobre os intelectuais e classe dirigente e sobre a elite eclesiástica; o de Carlos Hasenbalg e Nelson do Valle Silva (1989) sobre relações de raça e mobilidade social; a tese de Zairo Borges Cheibub (1984) sobre os diplomatas do Itamarati; e o livro de Luiz Werneck Vianna e colaboradores (1997) sobre a magistratura.

Em outro contexto, alguns autores trataram do tema burocracia para explicar a estruturação do poder político-administrativo no Estado brasileiro. Em Os Donos do Poder, Raimundo Faoro (1958) analisou em profundidade a estrutura burocrática brasileira a partir de uma visão weberiana clássica, enfatizando a questão das relações de poder em um Estado patrimonialista, onde o público e o privado nunca apresentaram limites muito claros. Em A Construção da Ordem e Teatro de Sombras, José Murilo de Carvalho (1997) estudou em detalhe a formação da elite burocrática brasileira como representante do poder, enfatizando a questão da formação intelectual 
entrelaçada com as raízes familiares. Em seu livro Bases do Autoritarismo Brasileiro, Simon Schwartzmann (1982) enfocou as contradições que emergiram entre o que se convencionou chamar de democracia brasileira e os discursos e práticas políticoadministrativas gerenciadas pela burocracia estatal, que sempre possuíram um claro traço autoritário, mesmo quando confundidas com as práticas populistas; além disso, Schwartzmann também apresenta uma inequívoca preocupação espacial ao explicar as diferenças regionais dos conflitos entre o governo central e os estados mais estruturados politicamente.

Outros autores enfocaram especificamente a questão da tecnoburocracia estatal, onde são formados quadros especializados, que detém o controle das atividades produtivas e de planejamento estratégico do Estado, além do monopólio da informação, via saber técnico. Nesta linha estão autores como Carlos Estevan Martins (1974), Fernando Henrique Cardoso (1975), Bresser Pereira (1980), Wanderley Guilherme dos Santos (1982), Sonia Draibe (1985), Gilda Portugal Gouveia (1994) e Edson Nunes (1985 e 1997), que discutem a formação da tecnoburocracia utilizando conceitos como insulamento burocrático, anéis burocráticos, ilhas de racionalidade técnica, universalismo de procedimentos e corporativismo. Esses termos, que de uma forma ou de outra, tentam explicar a formação e fortalecimento de um corpo técnico que controla alguns núcleos de atividades estatais supostamente excluídas das pressões político partidárias.

No campo antropológico, Lívia Barbosa (1999) discute a noção de meritocracia no Brasil estabelecendo comparações com o Japão e com os Estados Unidos. O tema é pertinente, sobretudo quando se tem em conta a magnitude do processo de formação de quadros técnicos que o IBGE gerenciou em boa parte desses 60 anos de sua existência.

No contexto brasileiro, assim como em outros países, a dicotomia estabelecida entre o político e o técnico nas áreas de governo inicia sua trajetória na década de 20 , ao findar a I Guerra Mundial. o profissional que melhor encarna este processo é o engenheiro encarregado de obras públicas, escudado na ampliação das áreas de especialização das Escolas Politécnicas. Sua atuação objetiva passa a contrastar com a lentidão das decisões políticas que, necessariamente, utilizavam alguns expedientes de acertos partidários ou mesmo de geração de conflitos entre as diferentes faç̧ões políticas.

Com isso toma corpo na sociedade um pensamento que divide a elite de governo em dois grupos: um com características negativas - o político - e outro com características positivas - o técnico. Ângela de Castro Gomes (1994) historia muito bem o tema, e José Luciano de Mattos Dias (1994) é altamente esclarecedor acerca do processo de ampliação do prestígio dos engenheiros no governo brasileiro.

21 Vale assinalar que, por ocasião da fundação dos Conselhos de Estatística e de Geografia nos anos 30, a composição majoritária das Assembléias e Conselhos Diretores era de profissionais oriundos dos cursos de Engenharia Civil e Militar. Figuras chave na criação do Conselho de Geografia e colaboradores freqüentes na Revista Brasileira de Geografia, como Cristóvão Leite de Castro, Silvio Fróes de Abreu e Moacir Silva, eram engenheiros.

22 É a partir dos anos 60 que os economistas irão se constituir como a segunda grande força nessa elite da tecnoburocracia, tanto no Brasil (Motta, 1994; Bielschowsky, 1995; Biderman, Cozac \& Rego, 1996; Loureiro, 1997), quanto na França (Fourquet, 1980). Em ambos países, boa parte desses profissionais iniciou sua carreira na Engenharia, tendo migrado posteriormente para a Economia. 
23 É sobre uma parcela dessa tecnoburocracia que trata a próxima seção, tomando como referência a estruturação inicial do Sistema de Planejamento Territorial Brasileiro. 0 foco incidirá, sobretudo sobre as ações de Mário Augusto Teixeira de Freitas objetivando uma revisão da divisão territorial do país, durante o Estado Novo.

\section{A formação institucional do Sistema de Planejamento Territorial Brasileiro}

Muitas podem ser as formas de interpretação sobre a formação e o desenvolvimento do que aqui propomos chamar de Sistema de Planejamento Territorial Brasileiro. ${ }^{1}$ Os trabalhos de Antônio Carlos Robert Moraes sobre o assunto, referenciados no Brasil colonial, são um bom exemplo de uma dessas múltiplas formas de abordagem (Moraes, 1983 e 1991). Maurício de Almeida Abreu também trabalhou a questão, sob o ponto de vista das relações entre o esquema jurídico colonial português em relação à apropriação do território e suas configurações espaciais, que nos foram legadas (Abreu, 1997).

Se considerarmos, no entanto, o marco político-administrativo da Revolução de $1930,{ }^{2}$ podemos argumentar que os responsáveis pelo gerenciamento do aparato de Estado do governo Vargas foram insuperáveis na preocupação com as questões referentes ao controle do território de forma mais abrangente. Esta afirmação se justifica ainda mais se levarmos em conta que a questão da unidade político-territorial brasileira no final da República Velha era um assunto delicado, pois as elites de estados fortes no campo político e militar, como São Paulo, Minas Gerais ou Rio Grande do Sul, poderiam criar movimentos emancipatórios que colocariam em risco a unidade nacional (como São Paulo e Rio Grande do Sul criaram efetivamente, no início dos anos 30).

O exemplo de São Paulo em 1932, mostrou que a manutenção de tal "unidade nacional" teria de passar por vários caminhos, além do militar e o da representação política clássica. A intermediação técnica era um deles. Mas como montar um sistema de organização do aparelho estatal num território imenso e com tantas particularidades regionais?

Das inúmeras experiências realizadas no governo Vargas, as que tiveram maior notoriedade foram a criação do Departamento Administrativo do Serviço Público (DASP) em 1938, sob a orientação de Luís Simões Lopes, e do Instituto Nacional de Estatística - a agência que se tornaria o embrião do futuro IBGE -, organizado por Mário Augusto Teixeira de Freitas entre 1934 e 1936.

Desses grandes articuladores, o que combinava maior visão de futuro com um alto grau de experiência em informações territoriais, adquirida ao longo dos anos $20 \mathrm{em}$ Minas Gerais, era Teixeira de Freitas. Delegado Geral do Recenseamento do Estado de Minas, criador de um eficiente sistema de gerenciamento de informações que cobria todos os municípios do território mineiro, este personagem teve uma atuação tão inovadora que, em 1930, foi convidado para apresentar, na I Conferência Nacional de Estatística, suas propostas sobre o tema. Estas - as famosas "33 teses" - vieram ao conhecimento público sob a denominação Algumas Novas Diretivas Para o Desenvolvimento da Estatística Brasileira, publicadas posteriormente pelo IBGE com o título Teses Estatísticas (Freitas, 1994).

29 Tal apresentação acabou não se realizando, devido aos acontecimentos que culminaram no Golpe de Estado de outubro de 1930, mas a figura de Teixeira de Freitas ficou 
claramente marcada nas mentes de alguns responsáveis pelos novos destinos do Estado brasileiro, como no caso do militar Juarez Távora, ministro da Viação em 1930 e da Agricultura entre 1932 e 1934. Távora era ainda um dos participantes do "Gabinete Negro", ${ }^{2}$ que reuniu-se todas as noites de novembro de 1930, no Palácio Guanabara, para traçar esses destinos.

30 As articulações entre Teixeira de Freitas, Juarez Távora e Francisco Campos durante os primeiros anos da década de 30, geraram ações de grande importância para a criação de um sistema de planejamento centrado no gerenciamento de informações coletadas junto aos municípios. Essas informações englobariam um amplo leque que cobriria características físicas e ambientais, geodésico-cartográficas e estatísticas as mais diversas, abrangendo produção, circulação e consumo, infra-estrutura econômicosocial e o aparelho de estado em todas as suas instâncias. Em suas memórias, Juarez Távora (1974: 96-98) explicou com clareza o processo de aproximação entre sua necessidade de possuir um sistema estatístico referente à produção agrária (como Ministro da Agricultura) e as idéias mais abrangentes de uma agência estatística nacional tal como a sonhada por Teixeira de Freitas.

31 A experiência de Teixeira de Freitas foi adquirida em Minas Gerais, através de um modelo que centralizava fortemente as decisões operacionais nas mãos de um único gerente, que, durante o processo de normatização das informações, tinha seu poder compartilhado com os produtores e usuários dos dados a serem coletados. A participação de representantes das diversas secretarias estaduais, e mesmo de delegações da esfera municipal de grandes cidades, garantia uma ampla aceitação deste modelo, além de consolidar uma estrutura de eficiência, pois praticamente todas as instâncias do governo ficavam comprometidas com o projeto.

Concebido como uma super agência de informações, o Instituto Nacional de Estatística abrangeria a totalidade do território nacional em quase todos os aspectos, constituindo um dos principais fatores de coesão do governo Vargas. Sua estrutura de funcionamento contemplava todas as instâncias de governo e caracterizava o que podemos definir como Agência Capilarizada do Poder Central, isto é, um órgão de informações diretamente subordinado ao Gabinete da Presidência da República, mas com alcance até a instância municipal. As decisões sobre suas estratégias de ação eram tomadas de forma colegiada no Conselho Superior de Estatística, estrutura que seria mantida no Conselho Nacional de Geografia, criado posteriormente.

Apenas para fins de comparação, as agências do Departamento de Correios e Telégrafos também apresentavam alta capilaridade, mas não desempenhavam o mesmo papel junto ao Poder Central, uma vez que não detinham o poder de prestar informações sobre a realidade socioeconômica dos municípios.

Assim, o projeto de Teixeira de Freitas consistiu numa ação de governo da mais alta importância para Getúlio Vargas. Seus maiores incentivadores foram sem dúvida Juarez Távora, possivelmente por sua experiência no interior brasileiro como tenente da Coluna Prestes nos anos 20, e também Francisco Campos, por sua visão modernizadora do ensino universitário e da saúde pública, num país bastante carente de informações. Posteriormente, o segundo ministro da Educação Gustavo Capanema trataria de ampliar essas ações de governo, enfatizando também as relações entre o IBGE e o sistema educacional brasileiro (IBGE, 1941).

As 33 teses de Teixeira de Freitas (Freitas, 1994) foram as ferramentas utilizadas por essas autoridades para a consecução de um projeto de governo que, na década seguinte, 
após os trabalhos de apuração do Censo de 1940, iria gerenciar o sistema de planejamento territorial brasileiro.

A década de 30, portanto, principalmente em sua segunda metade, foi de muito trabalho para Teixeira de Freitas e seus auxiliares diretos. Foi nesse período que as noções de integração técnica entre Estatística, Geografia e Cartografia tomaram corpo, sobretudo em termos de preparação das equipes de profissionais que iriam gerenciar a referida agência a partir de então. Datam também dessa época os convênios internacionais para a organização de cursos universitários no Brasil, tais como a vinda de professores franceses para iniciarem os cursos de Geografia em São Paulo e no Rio de Janeiro, além da vinda de especialistas austríacos em Geodésia. Foi preciso articular com as diversas categorias profissionais da época os nomes dos conselheiros que iriam participar, tanto técnica como politicamente, do novo instituto.

É importante lembrar que neste período os engenheiros (civis e militares) eram, juntamente com os bacharéis de direito, as duas maiores forças profissionais com as quais o governo contava para a execução de suas ações. E foram provenientes dessas categorias a maioria dos conselheiros técnicos escolhidos. Além disso, Teixeira de Freitas cooptou auxiliares diretos, que, na década de 40 tornaram-se a elite dirigente do IBGE. Este seria o caso do engenheiro Cristóvão Leite de Castro, responsável pelo serviço de estatísticas territoriais do Ministério de Agricultura e principal organizador do núcleo de profissionais que iria formar o Conselho Brasileiro de Geografia, posteriormente Conselho Nacional de Geografia.

\section{Os planos de Redivisão Territorial e suas conseqüências práticas}

38 As preocupações de Teixeira de Freitas com o gerenciamento do território brasileiro, no sentido espacial do termo, são possivelmente anteriores a 1930; no entanto, elas tomaram um grande impulso após a instauração do Governo Provisório de Vargas, pois foi em 28 de outubro de 1932 (em plena ocorrência do movimento constitucionalista de São Paulo) que o autor apresenta no Instituto Histórico e Geográfico Brasileiro suas primeiras teses sobre a redivisão política do Brasil, publicadas na Revista da instituição (Freitas, 1935). ${ }^{4}$

Cinco anos mais tarde, a questão da redivisão das unidades federadas retornaria com maior vigor na agenda de Teixeira de Freitas. Em dezembro de 1937, após a instituição do Estado Novo, ele coloca em discussão um novo estudo, apresentado "perante um grupo de brasileiros de elevadas responsabilidades na direção dos negócios públicos" (Freitas, 1941: 533). Suas palavras iniciais mostram, sem sombra de dúvida, que a questão da divisão territorial era uma estratégia de governo vislumbrada num contexto de Estado forte, com grandes poderes discricionários. Apesar disso, a proposta anunciava-se como um balão de ensaio técnico, como é possível perceber no cuidado extremo com o discurso, além dos esboços de redivisão territorial apresentados (Freitas, 1941 e 1948), baseados em um estudo preliminar de João Segadas Viana (1940).

O reforço de autoridade de que a nova ordem política investiu o Poder Executivo trouxe possibilidades inéditas ao encaminhamento de alguns problemas fundamentais da organização nacional, que vinham reclamando há muito, mas em vão, pronta e enérgica solução.

Assim sendo, parece oportuno o estudo, por este seleto grupo de cidadãos, de que 
um esquema orgânico para as grandes diretrizes e que convenha submeter a restauração dos nossos quadros políticos, administrativos, sociais e econômicos, a fim de que a nova ordem de coisas estabelecidas, desde as suas realizações mais fundamentais, as garantias definitivas da Defesa Nacional, compreendida esta em toda sua latitude.

Desejaria, pois, que os concidadãos aqui reunidos por um generoso pensamento se dispusessem a colaborar no preparo de um escorço geral daquelas diretrizes e, iniciando a tarefa pela questão mais geral e mais fundamental, apresentassem à consideração do Governo o plano preliminar da redivisão territorial do país.

Mas, como urge talvez aproveitar as possibilidades excepcionais que abrem à Nação, neste momento, a sintonia espiritual e a solidariedade estreita das suas forças vivas em torno do ideal generoso de erguimento de uma Pátria combalida ao nível exato da sua capacidade de vencer, das suas aspirações, da sua vocação e dos recursos esplêndidos com que a Providência Divina a galardoou; - pois que assim acontece, peço permissão aos ilustres compatriotas que me ouvem, para colocar desde logo ante suas vistas, ainda que mui perfunctoriamente, o esboço que se me formou no espírito como fruto de um longo meditar sobre o palpitante tema aludido (Freitas, 1941: 533-34).

A questão central era a tentativa de equivalência territorial entre as unidades federadas a fim de se evitar as disparidades regionais, que, segundo Teixeira de Freitas, eram o grande problema da federação: "Quando suas Unidades tiverem relativa equivalência de área, a assegurar-lhes equivalência de potencial político, destinada a traduzir-se mais tarde em efetiva "equipotência" [se atingirá o equilíbrio necessário em benefício do todo nacional] (Freitas, 1941: 536). Para isso, Teixeira de Freitas define um padrão de tamanho territorial entre 250 e 350 mil km² e propõe a estratégia de associação entre Estados "sem diminuição para nenhum, e sem desigualdade, mas com o engrandecimento para todos, transformando-se em departamentos autônomos, subfederados para formar Estados compósitos - adstritos ao padrão, cada um dos quais com uma capital especialmente construída em um município neutro, que se localizaria quanto possível em ponto de convergência dos limites dos atuais Estados que passassem a associados" (id., ibid.: 537).

41 Mas o plano vai muito mais além, como se pode notar a partir das proposições envolvendo Minas Gerais, Estado "cujo espírito de brasilidade pode e deve ser aproveitado para aglutinar o poderoso núcleo central do novo sistema, sem prejudicarlhe o equilíbrio, venha ele a formar, com seu território somado aos do Espírito Santo, Rio de Janeiro e Distrito Federal, três futuros Estados, um com o Oeste e o Triângulo Mineiro (cujos anseios de autonomia ficariam atendidos) e outros dois marítimos (como também desejam as respectivas populações)" (id., ibid.: 537).

Minas acolheria temporariamente em Belo Horizonte a Capital Federal, preparando deste modo sua localização futura no Planalto Goiano (id., ibid.: 537). Este processo de mudança redefiniria o papel da cidade do Rio de Janeiro, que, perdendo o status de Capital Federal, receberia em troca a "vantajosa investidura de Capital de uns dos Estados mais ricos, mais populosos, mais prósperos e mais favorecidos pelo Governo Nacional, que tal seria o Estado da Mantiqueira, formado, com a divisão departamental conveniente, pelo Estado do Rio (mantida sua autonomia como um dos departamentos), o sul e a Zona da Mata de Minas Gerais (id., ibid.: 537).

43 Como se pode deduzir, uma estratégia desse porte não se deixaria distinguir apenas num trabalho acadêmico realizado por um único indivíduo. Houve muita articulação no núcleo do novo governo, antes e depois das apresentações de Teixeira de Freitas de 1932 e 1937. Além disso, outros autores também deram suas contribuições ao tema, 
como João Segadas Viana, major do Exército, que também já havia exposto uma proposta de divisão territorial na Revista Brasileira de Geografia (Viana, 1940). Tal proposta consistia na criação de 67 unidades administrativas (1 Distrito Federal, 27 Estados e 39 Territórios), que podem ser apreciados ma figura abaixo, anexada pelo autor na publicação referida.

\section{Divisão territorial do Brasil}

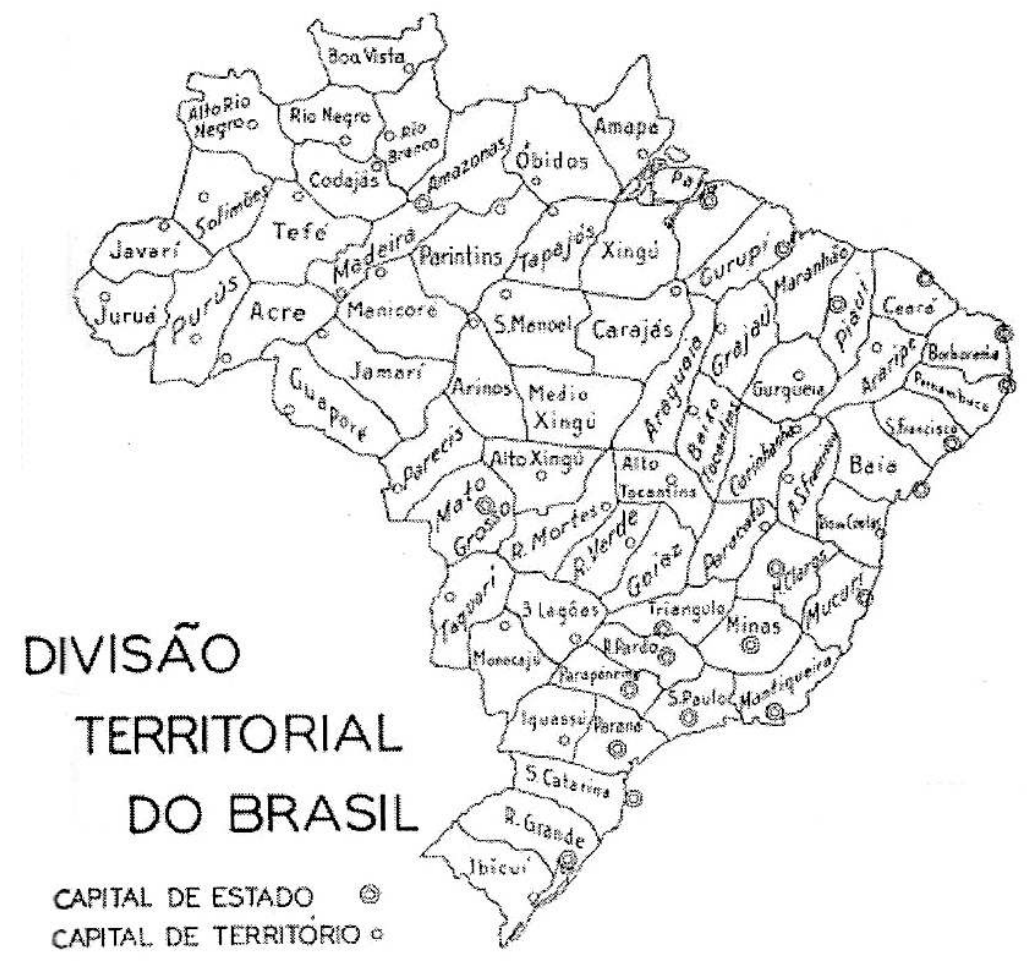

Em seu estudo, Segadas Viana procura levar em conta experiências de outros países que também enfrentaram a questão da divisão territorial, tais como Alemanha, França e Estados Unidos. Suas propostas de solução, porém, envolviam um curioso sistema de punições e prêmios. Punições para os Estados mais poderosos, territorial e politicamente - Rio Grande do Sul e São Paulo, que já haviam tentado movimentos emancipatórios - e prêmios para Estados que absorvessem bem as modificações na malha territorial. Segadas Viana havia colaborado com Teixeira de Freitas na elaboração do trabalho apresentado em 1937; suas proposições, portanto, em termos técnicos, não diferiam muito das daquele autor. O que as distinguia era o tom menos conciliador.

A Constituição de 1937 (redigida por Francisco Campos) de certa forma acomodou a questão, pois, se no aspecto político ela reduziu drasticamente a autonomia dos Estados, no espacial ela preservou o quadro territorial brasileiro. No entanto, outras ações de cunho geográfico foram implementadas, sendo duas delas marcantes. Uma foi a Lei Geográfica do Estado Novo, ou Decreto-Lei 311 de 02/03/1938, que dispunha sobre a delimitação das malhas municipais e distritais e definia ainda regras específicas sobre o mapeamento e a racionalização da toponímia (não poderia haver municípios homônimos num mesmo Estado). A outra foi a macro regionalização do país, oficializada pela Resolução 72 de 14/07/1941 da Assembléia Geral do Conselho Nacional 
de Geografia (IBGE,1952), que adotou os resultados do estudo de Fábio de Macedo Soares Guimarães e sua equipe (Guimarães, 1941).

No caso da Lei Geográfica, a necessidade de bases cartográficas confiáveis para a campanha censitária de 1940 induziu os técnicos do IBGE a promover estudos visando a uniformização das circunscrições territoriais dos municípios e seus distritos. Com a referida Lei, o IBGE passou a controlar a conformação espacial das malhas municipais e distritais através de critérios técnicos que envolviam extensão territorial, população e receita; além disso, assegurou a unicidade da toponímia por meio da verificação de homônimos.

Entre os primeiros resultados das Campanhas Geográficas realizadas na segunda metade dos anos 30, dois foram mais importantes: 1) a definição dos limites dos 1.574 municípios e 4.841 distritos, descrevendo todos os acidentes naturais que referenciavam esses limites; e 2) o esforço de mapeamento sistemático dos territórios municipais, que as prefeituras, com o apoio técnico do IBGE, realizaram por determinação do artigo 13 da Lei Geográfica, sob pena de cassação da autonomia municipal.

Essas duas realizações asseguraram uma base cartográfica confiável à Campanha Censitária de 1940 e foram solenemente apresentados ao Presidente Getúlio Vargas no dia 24 de março de 1940, em Curitiba, por ocasião das Exposições Regionais dos Mapas Municipais. Para garantir um alcance nacional ao evento o presidente do IBGE, Embaixador José Carlos de Macedo Soares, saudou todos os envolvidos no processo por via radiofônica especial, utilizando o sistema da Hora do Brasil (hoje Voz do Brasil), coordenado pelo Departamento de Imprensa e Propaganda (DIP).

Tal sistema perduraria até a Constituição de 1988, que, por conta de uma nova noção de autonomia, decidiu liberar para os respectivos legislativos estaduais e municipais as ações que envolvem emancipações municipais e distritais, com alterações nas malhas. Com isso, o número de municípios saltou de 3.974 em 1980 para 4.491 em 1990, elevando-se para 5.505 em 1997 e perdeu-se o controle sobre os homônimos, que já atingiam a cifra de 483 municípios em 1997.

50 No que concerne ao processo de regionalização, sua principal finalidade no início dos anos 40, era a de homogeneizar territórios de características fisiográficas semelhantes, a fim de garantir uma uniformização de procedimentos nos estudos geográficos e no processo de coleta estatística. Uma ressalva fundamental foi definida: não era possível desmembrar uma unidade da federação num processo de regionalização.

51 Nas palavras de Eli Alves Penha:

“A divisão regional do Brasil ficou, por fim, constituída sucessivamente em Grandes Regiões (Norte, Nordeste, Leste, Centro-Oeste e Sul), Regiões Fisiográficas (em número de 31), Sub-regiões (66), Zonas (aproximadamente 160), obtidas em segunda aproximação pela consideração das características fisionômicas (naturais e humanas) dos municípios brasileiros.

Foi atribuído aos órgãos regionais de Geografia e Estatística empreenderem os estudos sobre a divisão regional dos respectivos Estados, segundo o critério geográfico pelo qual se agrupariam municípios que apresentassem características naturais e humanas afins, consentâneas com a caracterização fisionômica do conjunto do Território Nacional.

Esta divisão regional, tal como foi estabelecida pelo $\mathrm{CNG}$, se generalizou no país obedecendo às determinações do Presidente Vargas a fim de atender à administração pública. Exatamente como nos dois primeiros séculos da fase 
colonial, quando o governo central procurou ajustar a divisão territorial dentro de um quadro optimum de administração, deixando que as unidades constituíssem seus limites 'espontaneamente"' (Penha, 1993: 108).

Nos períodos posteriores, o processo de regionalização assumiu tanto a função de servir de base para divulgação de dados estatísticos como a de subsidiar o processo de planejamento, classificando áreas homogêneas (Regiões Fisiográficas, Regiões Homogêneas e posteriormente Regiões Geográficas) ou determinando pólos geradores de atividades ou de receitas, conforme um objetivo pré-determinado (Regiões de Influência de Cidades). Tais procedimentos, fundamentais num órgão geográfico de âmbito governamental, são ainda hoje a principal área de atuação do Departamento de Geografia do IBGE.

\section{BIBLIOGRAFIA}

ABREU, Maurício de Almeida (1997). “A Apropriação do Território no Brasil Colonial”. In: CASTRO. Iná Elias et alii (orgs.) Explorações Geográficas. Rio de Janeiro, Bertrand Brasil, pp. 197-245.

BAER, Werner (1966). A Industrialização e o Desenvolvimento Econômico do Brasil. Rio de Janeiro, FVG. BAER, Werner; KERSTENETZKY, Isaac \& VILLELA, Aníbal (1975). “As Modificações no Papel do Estado na Economia Brasileira”. In BAER, Werner. A Industrialização e o Desenvolvimento Econômico do Brasil. Rio de Janeiro, FVG, $2^{\text {a }}$ ed.

BAER, Werner \& VILLELA, Aníbal (1975). “Crescimento Industrial e Industrialização: revisões nos estágios do desenvolvimento econômico do Brasil”. In: BAER, Werner. A Industrialização e o Desenvolvimento Econômico do Brasil. Rio de Janeiro, FVG, $2^{\mathrm{a}}$ ed.

BARBOSA, Lívia (1999). Igualdade e Meritocracia. Rio de Janeiro, FGV.

BIDERMAN, Ciro; COZAC, Luis Felipe L. \& REGO, José Marcio (1997). Conversas com Economistas Brasileiros. Rio de Janeiro, Editora 34.

BIELSCHOWSKY, Ricardo (1995). Pensamento Econômico Brasileiro: o ciclo ideológico do desenvolvimento. Rio de Janeiro, Contraponto, $2^{\mathrm{a}}$ ed. rev.

CARDOSO, Fernando Henrique (1975). Autoritarismo e Democratização. São Paulo, Paz e Terra.

CARVALHO, José Murilo de (1996). A Construção da Ordem / Teatro de Sombras. Rio de Janeiro, Editora da UFRJ / Relume Dumará.

CHEIBUB, Zairo Borges (1984). Diplomacia, Diplomatas e Política Externa: aspectos do processo de institucionalização do Itamaraty. Dissertação de Mestrado. Rio de Janeiro, IUPERJ.

D’ARAUJO, Maria Celina (org.). (1999). As Instituições Brasileiras da Era Vargas. Rio de Janeiro, FGV / EdUERJ.

DIAS, José Luciano de Mattos (1994). “Os engenheiros do Brasil”. In: GOMES, Ângela de Castro (coord.). Engenheiros e Economistas: as novas elites burocráticas. Rio de Janeiro, FGV, pp. 13-81. 
DRAIBE, Sônia (1985). Rumos e Metamorfoses: Estado e industrialização no Brasil, 1930-1960. Rio de Janeiro, Paz e Terra.

FAORO, Raimundo (1973). Os Donos do Poder: formação do patronato político brasileiro. São Paulo, Globo.

FAUSTO Boris (1987). A Revolução de 1930: Historiografia e História, São Paulo, Brasiliense.

FOURQUET, François (1980). Les Comptes de la Puissance: histoire de la comptabilité nationale et du plan. Paris, Encres.

FREITAS, Mário Augusto Teixeira de (1935). “Conferência realizada no IHGB em 28 de outubro de 1932”. Revista do Instituto Histórico e Geográfico Brasileiro v. 166, pp. 764-805.

. (1941). “A Redivisão Política do Brasil”. Revista Brasileira de Geografia v. 3, nº 3, pp. 533-534.

(1948). A Redivisão Política do Brasil. Rio de Janeiro, CNG/IBGE.

. (1994). "Teses Estatísticas". Teixeira de Freitas: pensamento e ação. (Documentos para

disseminação. Memória Institucional, no 1). Rio de Janeiro, IBGE, pp. 17-76.

(1994). "Instituto Nacional de Estatística" (Integra do discurso do ato de instalação do INE em 29/05/1936). Teixeira de Freitas: pensamento e ação. (Documentos para disseminação. Memória Institucional, $\mathrm{n}^{\circ}$ 1). Rio de Janeiro, IBGE, pp.103-130.

GOMES, Ângela de Castro (1994). "Novas Elites Burocráticas”. In GOMES, Ângela de C. (coord.). Engenheiros e Economistas: novas elites burocráticas. Rio de Janeiro, FGV, pp. 1-11.

GOUVEIA, Gilda Portugal (1994). Burocracia e Elites Burocráticas no Brasil. São Paulo, Paulicéia.

GUIMARÃES, Fábio de Macedo Soares (1941). “Divisão Regional do Brasil”. Revista Brasileira de Geografia v. 3, n. 2 (Reimpressão no v. 50, t. 1, 1988. Número especial).

HASENBALG, Carlos \& SILVA, Nelson do Valle (1989). Estrutura Social, Mobilidade e Raça. Rio de Janeiro, Vértice.

IBGE (1941). O Instituto Brasileiro de Geografia e Estatística e a Educação: elucidário apresentado à Primeira Conferência Nacional de Educação, 2vol. Rio de Janeiro.

IBGE (1952). Coletânea de Leis e Decretos Relativos ao Conselho Nacional de Geografia. Rio de Janeiro.

LOUREIRO, Maria Rita (1997). Os Economistas no Governo. Rio de Janeiro, FGV.

MALAN, Pedro S. et alii (1977). Política Econômica Externa e Industrialização no Brasil, 1932/1952.

(Relatório de Pesquisa, no 36). Rio de Janeiro, IPEA/INPES.

MALIN, Mauro \& PENCHEL, Marcos A. (1994). "Francisco Campos”. In BELOCH, Israel (coord.). Dicionário Histórico-Biográfico Brasileiro. Rio de Janeiro, FGV.

MARIANI, Maria Clara \& FLAKSMAN, Dora Rocha (1994). "Luís Simões Lopes". In: BELOCH, Israel (coord.). Dicionário Histórico-Biográfico Brasileiro. Rio de Janeiro, FGV.

MARTINS, Carlos Estevan (1974). Tecnocracia e Capitalismo: a política dos técnicos no Brasil. São Paulo, Brasiliense.

MICELI, Sérgio (1979). Intelectuais e Classe Dirigente no Brasil. São Paulo, Difel.

(1988). A Elite Eclesiástica Brasileira. Rio de Janeiro, Bertrand Brasil.

MORAES, Antônio Carlos Robert (1983). Historicidade, Consciência e Construção do Espaço: notas para um debate. Métodos em Questão, nº 18. São Paulo, IG-USP. 
. (1991). Bases da Formação Territorial do Brasil. o território colonial brasileiro no "longo" século XVI. Tese de Doutorado. São Paulo, Departamento de Geografia, USP.

MOTTA, Marly da Silva (1994). "Economistas: intelectuais e 'mágicos”'. In: GOMES, Ângela de Castro (coord.). Engenheiros e Economistas: novas elites burocráticas. Rio de Janeiro, FGV, pp. 82-140.

MOTOYAMA, Shozo (ed.). (1994). Tecnologia e Industrialização no Brasil. São Paulo, UNESP.

NUNES, Edson de Oliveira (1985). “Tipos de Capitalismo. Instituições e Ação Social: notas para uma sociologia política do Brasil contemporâneo". Dados v. 28, n. 3, pp. 18-35.

(1985). A Gramática Política do Brasil: clientelismo e insulamento burocrático. Rio de Janeiro, Zahar/ENAP, 1997.

PANDOLFI, Dulce (org.). (1999). Repensando o Estado Novo. Rio de Janeiro, FGV.

PANTOJA, Silvia Regina \& CAMARINHA, Daniel (1994). “Juarez Távora”. In BELOCH, Israel (coord.). Dicionário Histórico-Biográfico Brasileiro. Rio de Janeiro, FGV,

PENHA, Eli Alves (1993). A Criação do IBGE no Contexto da Centralização Política do Estado Novo. (Documentos para disseminação. Memória institucional, nº 4). Rio de Janeiro, IBGE.

PEREIRA, Luiz Carlos Bresser (1980). A Sociedade Estatal e a Tecnoburocracia. São Paulo, Brasiliense. SANTOS, Wanderley Guilherme dos (1992). “Fronteiras do Estado Mínimo: indicações sobre o híbrido institucional brasileiro". In: VELLOSO, João Paulo dos Reis (coord.). O Brasil e as reformas políticas. Rio de Janeiro, José Olímpio.

SKIDMORE, Thomas (1975). Brasil: de Getúlio a Castelo. Rio de Janeiro, Paz e Terra.

TAVORA, Juarez (1974). Uma Vida e Muitas Lutas, vol.2: A Caminhada no Altiplano. Rio de Janeiro, José Olímpio,

VIANA, João Segadas (1940). “Divisão Territorial do Brasil”. Revista Brasileira de Geografia, v. 2, nํ3, pp. 372-406.

VIANNA, Luiz Werneck et alii (1997). Corpo e Alma da Magistratura Brasileira. Rio de Janeiro, Revan.

VILLELA, Annibal V. \& SUZIGAN, Wilson (1975). Política do Governo e Crescimento da Economia Brasileira: 1889-1945. Rio de Janeiro, IPEA.

WEBER, Max (1974). "Parlamentarismo e Governo Numa Alemanha Reconstruída”. In: Os Pensadores. Max Weber. São Paulo, Abril.

\section{NOTAS}

1. A expressão não era empregada na Era Vargas, porém, o conjunto de demandas geradas pelo governo em termos de regionalização do território (macroregiões, projetos de desenvolvimento de bacias hidrográficas, regiões e zonas fisiográficas) era claramente o embrião do sistema referido.

2. Para uma visão mais abrangente do contexto político em que se estruturou o movimento de 1930 e seus desdobramentos posteriores, recomenda-se a leitura de Rumos e Metamorfoses (Draibe, 1985) e A Revolução de 1930: Historiografia e História (Fausto, 1987).

3. Além de Juarez Távora, o grupo era composto por José Fernandes Leite de Castro, Osvaldo Aranha, Ari Parreiras, José Américo de Almeida, Pedro Ernesto Batista, João Alberto e Francisco Campos, titular do recém criado Ministério da Educação e Saúde Pública (Pantoja e Camarinha, 1984; Malin e Penchel, 1984). 
4. Um breve histórico sobre o tema foi desenvolvido por Eli Alves Penha, mostrando que o assunto já havia preocupado as autoridades portuguesas e brasileiras desde o século XVI (Penha, 1993:105).

\section{ÍNDICE}

Índice geográfico: Brasil

Índice cronológico: 1930, 1945

\section{AUTOR}

\section{ROBERTO SCHMIDT DE ALMEIDA}

Ex-pesquisador titular da Equipe de Memória Institucional do IBGE (CDDI); consultor do IBREFGV.

almeidar@br.inter.net 